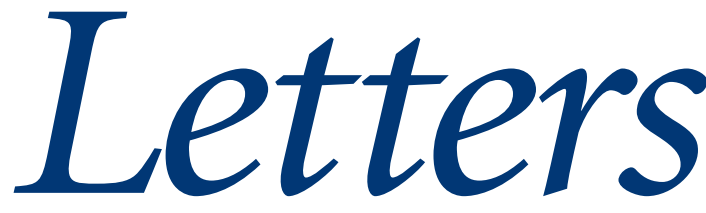

All letters are subject to editing and may be shortened. Letters should be sent to the BJGP office by e-mail in the first instance, addressed to

journal@rcgp.org.uk (please include your postal address). Alternatively, they may be sent by post as an MS Word or plain text version on CD or DVD. We regret that we cannot notify authors regarding publication. Letters not published in the Journal may be posted online on our Discussion Forum. For instructions please visit: http://www.rcgp.org.uk/bjgp-discuss

\section{Assisted dying}

David Jewell uses his position as Editor of the BJGP to provide us with his personal views on assisted suicide in the November issue; ${ }^{1}$ but I feel that some of his comments must not go unremarked upon.

He correctly notes that GPs 'remain an important presence in palliative care', thus our collective opinions must make a valuable contribution to the debate. Yet we are but members of wider society, and it is that wider society which will decide where it wants to travel with this. The idea that we have a 'belief that if we oppose any change strongly enough our view will prevail' must be nonsense: goodness! How much have governments changed the ways we work or the things we do very much against our collective will.

But I'm seeking common ground here, and we both share the view that GPs can make a valuable contribution. It is exactly that desire to seek common ground that leads to a situation where 'most of the arguments are not about principle ... but about the consequences or practicalities'. There are of course opinions that arise from a more spiritual point of view, and each faith group will represent their own perspective, as will humanists, secularists, and aetheists. But it is striking that an organisation such as Care Not Killing can bring together an otherwise diverse group of disability and human rights organisations, healthcare and palliative care groups, and faith-based organisations to make sure that objections to physician-assisted suicide are made clear. ${ }^{2}$ From where I stand, our society seems to be becoming increasingly secularised; it talks about tolerance and respect, yet any other firm faith-based viewpoint seems to be becoming less and less tolerated (almost to the point where, professionally, you are not allowed to talk about it at all). Jewell represents one clear strand of thought but there is in fact a large and very broad based support for an alternative, and they approach it through their common ground.

Our country, our society, is unique still, even though we are part of a wider global society that is in many ways becoming more uniform. I don't believe that we show 'an insular unwillingness to learn from experiences elsewhere'; rather, our own attitudes and opinions should be, and are, informed by those experiences; but that does not mean that we should necessarily always take the same route as other countries (and in many other societal or political aspects there is widespread support for remaining out of step with much of Europe, for example).

Contemporary societal attitudes do indeed seem to have 'elevated patient autonomy to the point where it outweighs almost every other ethical principle', but I actually think that is very wrong. We are a society, bound together inextricably, not simply a very large bunch of individuals. We do each have rights but, to me,

fundamentally more important are our duties and responsibilities to each other, and each of us needs to consider these before any of us demand our rights.

Finally, while I can find some common ground with Jewell and disagree with his conclusions, I absolutely refute that in the 'messiness and unpredictability of life' we should 'abandon our commitment' to patients in any way. I intend to travel that path with my patients until death indeed parts us in this world, doing my best to relieve suffering. Actually, the really hard part for everyone is coping with the very fact that life is messy and unpredictable, and accepting that as humans we are not Gods.

\section{Mick Leach,}

28/30 Kings Road, Harrogate,
North Yorkshire, HG1 5JP.

E-mail: Mick.Leach@gp-b82013.nhs.uk

\section{REFERENCES}

1. Jewell D. Our debt to those who are dying. Br J Gen Pract 2009; 59(568): 809-810.

2. Care not killing. http://www.carenotkilling.org.uk (accessed 9 Nov 2009).

DOI: 10.3399/bjgp09X473178

\section{Assisted dying}

I was surprised, shocked, and saddened to read your personal opinions of assisted dying expressed in an editorial in the November issue of the Journal. ${ }^{1}$ If you do insist on giving your own personal views on such a controversial issue, please be gracious enough to allow others to give an alternative view particularly when, as you acknowledge, your view is in the minority. Preferably dear Editor, kindly stick to editing.

Hugh Alberti,

10 The Avenue, Middlesbrough, TS5 6PB.

E-Mail: Hugh.alberti@dur.ac.uk

\section{REFERENCE}

1. Jewell D. Our debt to those who are dying. Br J Gen Pract 2009; 59(568): 809-810.

DOI: 10.3399/bjgp09X473187

\section{Assisted dying}

In his thoughtful editorial on assisted suicide, ${ }^{1}$ David Jewell warns against medical paternalism and concludes by pointing out that doctors are '... not the public's masters but its servants'.

While I might agree with his assertion that '... the public understands these issue all to well', it is clear that such 
understanding has led to widely different views within it. Jewell suggests that doctors should inform the debate but not be involved in fundamental decision making, and this then raises the issue of who will, in fact, take on this responsibility. Jewell's suggestion that 'the public' will do so is disingenuous, given the obvious lack of unanimity of opinion within it. In any case, it seems curious to me for doctors to be urged to take such a passive role, when it is they who will be charged, quite literally, with the responsibility of delivering assisted suicide if it is introduced.

The risk here is that the voices of the politically powerful and influential will prevail. If they really want to safeguard the interests of their more vulnerable patients, doctors would do well to remember that there is a world of difference between being a public servant and a slave to majority public opinion.

\section{Roger Tisi,}

Audley Mills Surgery, Rayleigh, Essex, SS6 7JF. E-mail: rbtisi@googlemail.com

\section{REFERENCE}

1. Jewell D. Our debt to those who are dying Br J Gen Pract 2009; 59(568): 809-810.

DOI: 10.3399/bjgp09X473196

\section{Editor's comment}

Dr Alberti raises an important question, about the role of editors in setting the policy for journals. Mostly I have restrained myself from commenting: in 10 years this was, I think, only the third editorial I have published (there was a fourth that a trusted colleague persuaded me not to publish). But influence is exerted by the decisions on what to publish, which editorials are commissioned, and who is invited to write them. On this occasion I invited someone else, but when he declined I realised that I knew what content I wanted so decided not to hide behind someone else but to sign it myself $-E d$

\section{Obesity guidance}

\section{Mercer's discussion paper ${ }^{1}$ on the}

usefulness of clinical guidelines for the management of obesity in general practice is commendable and yet raises serious concerns.

It is misleading that the NICE obesity guidelines focus so much attention on drugs and bariatric surgery, neglecting the only true treatment (and prevention) options of lifestyle modification through increased physical activity and improved diet. In the summary NICE clinical guideline 43 , these get a single feeble line and this is a grossly misleading representation. One might also wonder how well equipped GPs currently are to, 'offering multi-component interventions to increase physical activity, increase healthy eating, and improve eating behaviour' during the average 9-minute consultation and when many GPs are not aware of the importance of physical activity. $^{2}$

This persistent focus away from physical activity and diet as the main primary and secondary prevention options are a worry and reflect educational needs and faults within modern medicine, where the true causes of chronic disease are neglected and forgotten, to an extent, to have been largely self-inflicted. Perhaps this is commercially driven by the pharmaceutical industry and the relative simplicity of researching drugs by RCTs with dichotomous outcomes (it works or it doesn't) against more complex long-term studies assessing physical activity and diet with numerous multi-end point outcomes. There are not much promising long-term data for obesity treatment with drugs, plenty of side effects, and none of the collateral benefits of regular physical activity, including the potential to treat and prevent over a dozen chronic conditions. ${ }^{3}$

NICE guideline 43 is also unjustified in promoting negative attitudes towards lifestyle improvements in primary care when these have not been researched. Evidence shows that even brief consultations (3-10 minutes) or simple pedometer-based programmes delivered through health professionals can lead to substantial increases in patients' activity levels (by approximately $30 \%$ ).

There is a lot of convincing evidence from exercise medicine alone to suggest that physical inactivity is the causal factor for most western chronic diseases (including obesity) rather than obesity per se. ${ }^{5}$ So, is it time to focus our resources on finding the best ways to achieve and sustain increased levels of physical activity and improvements in diet within primary care, rather than focusing on the unproductive symptom of obesity and increasing its societal stigma?

\section{Richard Weiler,}

Locum GP, Hertfordshire and Specialist Registrar in Sport \& Exercise Medicine, London Deanery.

E-mail: Richard.Weiler@uclmail.net

\section{Emmanuel Stamatakis,}

Senior Research Associate, National Institute for Health Research Post-Doctoral Fellow, University College London, Department of Epidemiology and Public Health.

\section{REFERENCES}

1. Mercer S. How useful are clinical guidelines for the management of obesity in general practice? $\mathrm{Br} J \mathrm{Gen}$ Pract 2009; 59(568): 863-868.

2. Gupta K and Fan L. Doctors: fighting fit or couch potatoes? Br J Sports Med 2009; 43(2): 153-154.

3. Kujala UM. Evidence on the effects of exercise therapy in the treatment of chronic disease. Br I Sports Med 2009; 43(8): 550-555.

4. Marcus BH, Williams DM, Dubbert PM, et al. Physical activity intervention studies: what we know and what we need to know: a scientific statement from the American Heart Association Council on nutrition, Physical Activity, and Metabolism (Subcommittee on Physical Activity); Council on Cardiovascular Disease in the Young; and the Interdisciplinary Working Group on Quality of Care and Outcomes Research. Circulation 2006; 114(24): 2739-2752.

5. Blair SN. Physical inactivity: the biggest public health problem of the 21st century. Br J Sports Med 2009; 43(1): $1-2$.

DOI: 10.3399/bjgp09X473204

\section{Familial hypercholesterolaemia}

Humphries et al report that a practice of 10000 patients is likely to have around 20 patients with familial hypercholesterolaemia who are at risk of premature coronary heart disease. ${ }^{1}$ They emphasise the importance of primary care in supporting adherence to lipid lowering treatment and lifestyle advice including exercise. Exercise is highly topical in view of the 2012 London Olympics and two recent UK government initiatives 'Be 